\title{
Effect of ornithine alpha ketoglutarate on disturbances of brain metabolism caused by high blood ammonia
}

\author{
I. M. JAMES, G. DORF, S. HALL, H. MICHEL, DRAGOSLAVA DOJCINOV, \\ G. GRAVAGNE, AND LINDSAY MacDONELL
}

From the Department of Medicine; Royal Free Hospital, London, and Departments of Medicine, Hotel Dieu (Paris), and Hôpital St Eloi Clinique Medicale A. (Montpellier)

SUMMARY The administration of ammonium salts to free ventilated dogs causes an increase in the anaerobic consumption of glucose.

Prior and simultaneous administration of the drug ornithine alpha ketoglutarate not only attenuates the rise in blood ammonia but also favourably affects these changes in brain metabolism.

In patients with severe hepatic encephalopathy there is a fall in cerebral blood flow and in cerebral oxygen consumption (Fazekas, Ticktin, Ehrmantraut, and Alman, 1956; Posner and Plum, 1960). There is in addition an abnormality in the handling of glucose by the brain which probably precedes the reduction in oxygen utilization (Bianchi Porro, Maiolo, and Della Porta, 1969; James, Nashat, Sampson, Williams, and Gerassini, 1969). Indeed it is probable that the abnormalities in glucose metabolism are not confined solely to the brain. Thus Klassen, Aronoff, and Karpati (1969) have demonstrated an increase in the production of lactic acid by tissues of the forearm in patients with hyperammonaemia who had chronic liver disease.

We have recently shown that when ammonium salts are given to free ventilating dogs, the glucose utilization by the brain is largely increased without similar changes in oxygen consumption. This anaerobic glycolysis results in lactic acidosis and hyperventilation. It would appear that no matter what type of salt is chosen the results are similar. These findings contrast with those previously described by us in dogs ventilated at a constant rate and volume where it was found that the more acid an ammonium compound the more likely a fall in oxygen consumption (James, Garassini, and Larbi, 1971). The ability to hyperventilate appears therefore to be of crucial importance in assessing the toxicity of various ammonium salts.

CORRESPONDENCE: Dr I. M. James, Department of Medicine, Royal Free Hospital, Gray's Inn Road, London, WC1X 8LF.

Received for publication 18 May 1972.
The drug ornithine alpha ketoglutarate has been widely used on the continent for a number of years for reducing blood ammonia levels in patients with encephalopathy.

Ornithine is a base and alpha ketoglutarate is a diacid. When combined in the proportions $2: 1$ a neutral salt is obtained.

The mechanism of this drug in lowering blood ammonia has recently been outlined by Michel, Ogé, and Bertrand (1971). In the liver a molecule of ammonia combines with carbonic anhydride and ATP, carbamyl-phosphate being formed. This then combines with ornithine to form citrulline, which is transformed into arginine on receiving a second $\mathrm{NH}_{4}{ }^{+}$group. Subsequently under the influence of arginase, urea and ornithine are formed. A total of two molecules of $\mathrm{NH}_{4}+$ have thus been transformed into urea.

In the peripheral tissues, alpha ketoglutarate fixes an $\mathrm{NH}_{4}+$ molecule and transforms it into glutamic acid which by collecting a second $\mathrm{NH}_{4}+$ molecule produces glutamine.

The fact that ornithine alpha ketoglutarate can lower blood ammonia concentrations in patients with liver disease has already been demonstrated by Michel et al (1971).

The purpose of the present experiment was to determine in dogs the way in which ornithine alpha ketoglutarate ${ }^{1}$ could affect the response of cerebral metabolism to an infusion of an ammonium salt.

Three parts of the experiment were planned. First, ammonium bicarbonate was given to dogs in a ${ }^{1}$ Kindly supplied as Ornicetil by Jacques Logeais Laboratories, Paris. 
sufficient quantity to elevate the blood ammonia concentration to levels similar to those found in patients with hepatic coma.

Following recovery the same quantity of ammonium bicarbonate was given but ornithine alpha ketoglutarate was given simultaneously.

Finally after a period of recovery double the quantity of ammonium bicarbonate was infused and at the same time ornithine alpha ketoglutarate. It was then planned to compare the changes resulting in brain oxygen and glucose consumption under the three conditions.

\section{Methods}

The experiments were carried out on five mongrel dogs of mean weight $18.0 \mathrm{~kg} \pm 3$ (SD).

They were anaesthetized at a dosage of $25 \mathrm{mg} / \mathrm{kg}$ body weight with sodium pentobarbitone and allowed to ventilate freely. The left femoral artery was cannulated with a polyethylene catheter and blood pressure continuously recorded by means of a damped mercury manometer. Arterial blood samples were obtained from the same source.

A branch of the left femoral vein was catheterized so that ammonium bicarbonate could be infused over a period of 15 minutes. The right femoral vein was also catheterized so that simultaneous infusions of alpha ketoglutarate were possible.

Cerebral (cortical) blood flow was measured by the method of Ingvar and Lassen (1962) using the intracarotid injection of ${ }^{85} \mathrm{Krypton}$.
A fine catheter was placed in the superior saggital sinus in such a way as not to impede flow but which enabled samples of cortical venous blood to be obtained.

Blood samples for oxygen content, glucose content, $p \mathrm{H}$, and $\mathrm{PCO}_{2}$ were taken from the superior saggital sinus thus enabling cerebral oxygen and cerebral glucose consumption to be calculated. Oxygen content was measured directly by the technique of Linden, Ledsome, and Norman (1965) and glucose by a glucose oxidase method (Trinder, 1969). The $p \mathrm{H}$ and $\mathrm{PCO}_{2}$ were measured with appropriate radiometer electrodes.

Blood ammonia was measured by the method of Dropsy and Boy (1961) using an AutoAnalyzer and continuous sampling (Michel, Gravagne, Sany, and Gabet, 1966). Arterial lactic acid levels were measured by the method of Hohorst (1963).

The measurement of flow and blood sampling were carried out at the end of each experimental period. The duration of each period in minutes can be seen from Table I. Ammonium bicarbonate was given, in all dogs, for a period of 15 minutes, on the first two occasions in a dose of $2 \mathrm{mg} / \mathrm{kg} / \mathrm{min}$ and finally in a dose of $4 \mathrm{mg} / \mathrm{kg} / \mathrm{min}$. Ornithine alpha ketoglutarate was always given in a dose of $20 \mathrm{mg} /$ $\mathrm{kg} / \mathrm{min}$.

The oxygen/glucose index has been calculated as an index of the anaerobic metabolism of glucose:

$$
\frac{\mathrm{A}-\mathrm{V} \mathrm{O}_{2}(\mathrm{mmole})}{6 \times \mathrm{A}-\mathrm{VG}(\mathrm{mmole})} \times 100 \%
$$

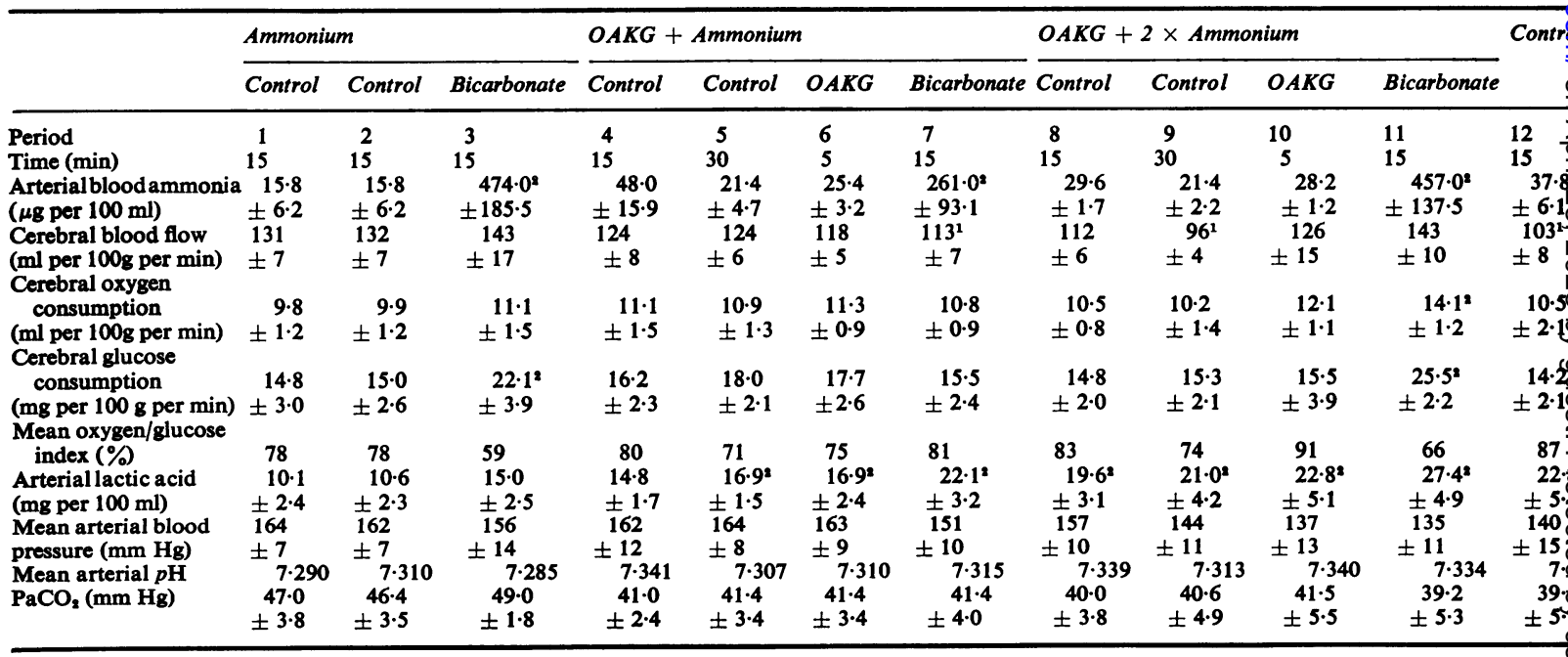

Table Effect of ammonium bicarbonate and ornithine alpha ketoglutarate (OAKG) on cerebral blood flow, oxygen, and glucose consumption in the dog 
Results

The administration of ammonium bicarbonate in a dose of $2 \mathrm{mg} / \mathrm{kg} / \mathrm{min}$ for 15 minutes caused not only a substantial rise in blood ammonia but also a $56 \%$ increase in glucose consumption and a $12 \%$ increase in oxygen consumption. There was a fall in the oxygen glucose index from 78 to $59 \%$ indicating increased anaerobic breakdown of glucose. Within 15 minutes, however, relative recovery had occurred.

Five minutes before the second infusion of ammonium bicarbonate, ornithine alpha ketoglutarate was given in a dose of $20 \mathrm{mg} / \mathrm{kg} / \mathrm{min}$. There was no consistent change in cerebral glucose consumption but there was in all animals a very small increase in oxygen consumption (this increase was just significant at the $5 \%$ level by paired analysis).

Ammonium bicarbonate given at the previous dose level during the ornithine alpha ketoglutarate infusion for 15 minutes effected a much less marked rise in blood ammonia and no consistent change in either cerebral oxygen or glucose consumption. Thus the mean oxygen/glucose index also remained unchanged.

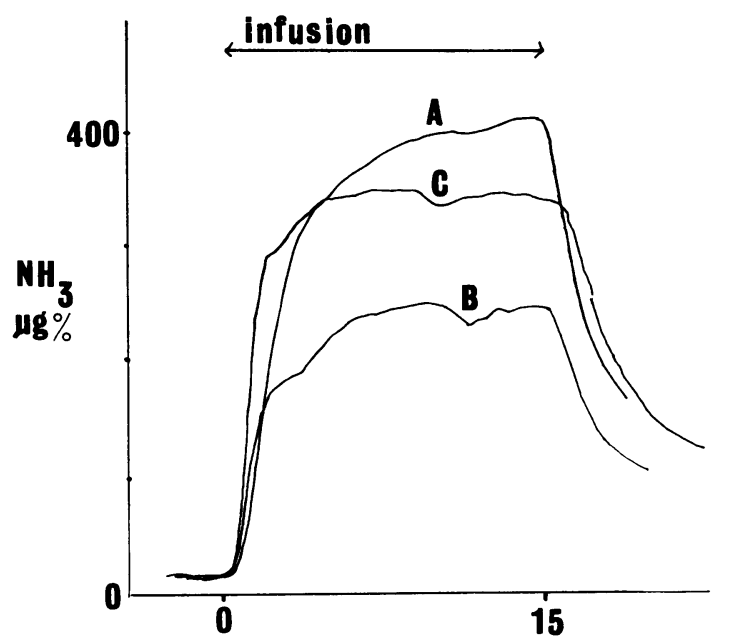

TimE ( $\min )$

Fig. The changes occurring in blood ammonia concentration in one dog with ammonium bicarbonate infusion and ornithine alpha ketoglutarate.

A Ammonium bicarbonate alone, $2 \mathrm{mg} / \mathrm{kg} / \mathrm{min}$, for 15 minutes

B Ammonium bicarbonate, $2 \mathrm{mg} / \mathrm{kg} / \mathrm{min}$, with ornithine alpha ketoglutarate $20 \mathrm{mg} / \mathrm{kg} / \mathrm{min}$

C Ammonium bicarbonate, $4 \mathrm{mg} / \mathrm{kg} / \mathrm{min}$, for 15 minutes with ornithine alpha ketoglutarate, $20 \mathrm{mg} / \mathrm{kg} / \mathrm{min}$.
Finally, a substantial elevation of blood ammonia levels was obtained at the same time as ornithine alpha ketoglutarate infusion by doubling the dose of ammonium bicarbonate. Thus similar levels of blood ammonia were obtained in period 11 as in period 3 (Table). Similar increases in glucose consumption occurred but on this latter occasion, due to an increase in oxygen consumption, the fall in oxygen glucose index was not as marked, ie, $74 \%$ compared with $66 \%$.

Changes in blood lactic acid levels are also shown in the Table. There was an increase in the lactic acid concentration throughout the experiment but it does appear that some accentuation of the rise in the order of $5 \mathrm{mg} / 100 \mathrm{ml}$ occurred on each occasion when ammonium salts were administered.

\section{Discussion}

THE EFFECT OF AMMONIUM BICARBONATE ON BRAIN METABOLISM

The administration of ammonium bicarbonate to dogs causes a large increase in glucose consumption by the brain. Since oxygen consumption is not similarly increased then some anaerobic breakdown of glucose must be occurring. As an index of the anaerobic breakdown of glucose by the brain the oxygen glucose index has been calculated.

In addition measurements of arterial lactic acid were made. These changes in arterial lactic acid, however, are not necessarily representative of changes in lactic acid production occurring in the brain. Furthermore it is possible, of course, for brain lactic acid production to be increased without a change in the glucose oxygen index if some of the oxygen is being diverted for the metabolism of substances other than glucose.

It has been suggested by Bessman and Bessman (1955) that depletion of alpha ketoglutarate to form glutamate and eventually glutamine is the reason for the failure of the tricarboxylic acid cycle in patients with high blood ammonia. This theory would fit in with our findings of disturbed oxygen glucose ratios and elevated glucose consumption. The increase in arterial lactic acid concentration could be explained by transient failure of the cycle.

However, it has also been argued that the lactic acidosis could equally well result from the inhibition of decarboxylation of pyruvate to acetyl CoA (McKhann and Tower, 1961). Klassen et al (1969) favoured this explanation since they found in their patients with hyperammonaemia that whereas lactic acid production by muscles was increased, fatty acid utilization was normal, ie, the citric acid cycle was functioning normally from acetyl CoA onwards. 
An inhibition of the decarboxylation of pyruvate to acetyl CoA would not fully account for the increase in brain glucose utilization that we have found. Some form of negative 'feedback' mechanism from the citric acid cycle affecting the rate of glucose utilization has to play a role. Since normal functioning of the cycle results in $\mathrm{CO}_{2}$ production and since it is known that elevated $\mathrm{CO}_{2}$ levels decrease (Xanalatos and James, 1972) and lowered $\mathrm{CO}_{2}$ levels increase glucose utilization by the brain (Alexander, Cohen, Wollman, Smith, Reivich, and Molen, 1965), such a postulate is not unreasonable. Furthermore, if a transient rise in intracellular brain $p \mathrm{H}$ due to a fall in $\mathrm{CO}_{2}$ is able to cause anaerobic breakdown of glucose by the brain so perhaps could a rise in $p \mathrm{H}$ due to a rise in ammonia concentration have the same effect.

THE EFFECT OF ORNITHINE ALPHA KETOGLUTARATE ON BRAIN METABOLISM

It has not been definitely shown that alpha ketoglutarate is able to pass the blood brain barrier but since an increase in cerebral oxygen consumption occurs in our present experiments this to us appears probable.

THE EFFECT OF AMMONIUM BICARBONATE ON BRAIN METABOLISM FOLLOWING THE PRIOR ADMINISTRATION OF ORNITHINE ALPHA KETOGLUTARATE

\section{Low dose of ammonium bicarbonate}

The attenuation of the rise in blood ammonia due to the prior administration of ornithine alpha ketoglutarate has already been described (Molimard, Morin, and Eskenazi, 1968).

There was on this occasion no change in cerebral oxygen or glucose consumption by the brain. If anything this is surprising, since with a level of blood ammonia of $261 \mu \mathrm{g} / 100 \mathrm{ml}$ one might expect some change in brain metabolism. However, it can be argued, if the theory of Bessman and Bessman is correct, that the alpha ketoglutarate is able to replete the deficiency caused by hyperammonaemia and therefore no disturbance in brain metabolism is found even with this level of blood ammonia.

Alternatively, if the theory of McKhann and Tower (1961) is correct and if a feedback mechanism exists, then ornithine alphaketoglutarate by increasing the activity of the citric acid cycle and increasing $\mathrm{CO}_{2}$ production could theoretically decrease glucose utilization.

The rise in arterial lactic acid that occurs is difficult to explain in the presence of a relatively normal oxygen glucose quotient. It may be possible that in the short term, if ornithine alpha ketoglutarate enters the cycle, some of the oxygen is diverted for its metabolism, allowing less for that of glucose. If this were the case then the increased $\mathrm{CO}_{2}$ production would eventually be expected to decrease the excess glucose utilization and lactic acid production.

\section{High dose of ammonium bicarbonate}

When ornithine alpha ketoglutarate was given with the higher dose of ammonium bicarbonate, similar blood ammonia levels were obtained as those when ammonium bicarbonate was given by itself at half the dose.

Thus with similar levels of blood ammonia the increase in glucose consumption was of the same order. On this occasion, however, an increase in oxygen consumption also occurred, which prevented so marked a fall in the oxygen glucose index. It is again difficult to evaluate the rise in the arterial lactic acid concentration which appears to have occurred, but as mentionedabove, some of this increase may be due to the fact that some of the oxygen is again being utilized in the metabolism of the alpha ketoglutarate fraction itself. The increased $\mathrm{CO}_{2}$ production which would result from this may be the reason for the fall in lactic acid concentration in the final control period.

It would appear therefore that ornithine alpha ketoglutarate is not only able to lower blood ammonia but is able to alter the response of cerebral metabolism in the experimental animal to an ammonium infusion.

Although there is some evidence to suggest that possibly the increase in arterial lactic acid due to ammonia intoxication is not abolished by the drug in these short-term experiments there is every reason for further investigation of the efficacy of this drug in the clinical situation.

\section{References}

Alexander, S. C., Cohen, P. J., Wollman, H., Smith, T. C., Reivich, M., and Vander Molen, R. A. (1965). Cerebral carbohydrate metabolism during hypocarbia in man. Anaesthesiology, 26, 624632.

Bessman, S. P., and Bessman, A. N. (1955). The cerebral and peripheral uptake of ammonia in liver disease with an hypothesis for the mechanism of hepatic coma. J. clin. Invest., 34, 622-628.

Bianchi Porro, G., Maiolo, A. T., and Della Porta, P. (1969). Cerebral blood flow and metabolism in hepatic cirrhosis before and after portacaval shunt operation. Gut, 10, 894-897.

Dropsy, G., and Boy, J. (1961). Détermination de l'ammoniémie (méthode automatique par dialyse). An. Biol. Clin., 19, 313-317.

Fazekas, J. F., Ticktin, H. E., Ehrmantraut, W. R., and Alman, R. W. (1956). Cerebral metabolism in hepatic insufficiency. Amer. J. Med., 21, 843-849.

Hohorst, H. J. (1963). Methods of Enzymatic Analysis, 1st ed., edited by H. U. Bergmeyer, pp. 266-270. Verlag Chemie, Weinheim.

Ingvar, D. H., and Lassen, N. A. (1962) Regional blood flow of the cerebral cortex determined by Krypton ${ }^{85}$. Acta physiol. scand., 54, 325-338.

James, I. M., Garassini, M., and Larbi, E. (1971). The effect of ammonium salts on cerebral and hind limb consumption of oxygen and glucose in the ventilated dog. Clin. Sci., 41, 403-408. 
James, I. M., Nashat, S., Sampson, D., Williams, H. S., and Garassini, M. (1969). Effect of induced metabolic alkalosis in hepatic encephalopathy. Lancet, 2, 1106-1108.

Klassen, G. A., Aronoff, A., and Karpati, G. (1969). Forearm metabolism in patients with chronic liver disease. Clin. Sci., 37, 455-470.

Linden, R. J., Ledsome, J. R., and Norman, J. (1965). Simple methods for the determination of the concentrations of carbon dioxide and oxygen in blood. Brit. J. Anaesth., 37, 77-78.

McKhann, G. M., and Tower, D. B. (1961). Ammonia toxicity and cerebral oxidative metabolism. Amer. J. Physiol., 200, 420-424.

Michel, H., Gravagne, G., Sany, C., and Gabet, R. (1967). Détermination de l'ammoniémie par automation dans la cirrhose alcoolique (technique de dosage, enregistrements nycthémériques et arterio-veineux). J. Med. Mont nellier, 2, 211-215.
Michel, H., Ogé, P., and Bertrand, L. (1971). Action de l'alphacétoglutarate d'ornithine sur l'hyperammoniemie du cirrhotique. Presse méd., 79, 867-868.

Molimard, R., Morin, R., and Eskenazi, P. (1968). Étude pharmacologique de l'alpha-cétoglutarate d'ornithine. Probl. Reanimat., 5, 869-879.

Posner, J. B., and Plum, F. (1960). The toxic effects of carbon dioxide and a cetazolamide in hepatic encephalopathy. J. clin. Invest., 39, 1246-1258.

Trinder, P. (1969). Determination of glucose in blood using glucose oxidase with an alternative oxygen acceptor. Ann. clin. Biochem., 6, 24.

Xanalatos, C., and James, I. M. (1972). Effect of arterial CO, pressure on the response of cerebral and hind limb blood flow and metabolism to isoprenaline infusion in the dog. Clin. Sci., 42, 63-68.

\section{The June 1972 Issue}

\section{THE JUNE 1972 ISSUE CONTAINS THE FOLLOWING PAPERS}

Lithogenic bile in patients with ileal dysfunction R. HERMON DOWLING, G. DUNCAN BELL, AND JUNE WHITE

Renal blood flow in malignant disease of the liver M. C. KEW, CAROL A. LIMBRICK, R. R. VARMA, AND SHEILA SHERLOCK

Cell-mediated immune reactivity in liver disease P. A. BACON, H. BERRY, AND R. BOWN

Two cases of Whipple's disease showing clinical and morphological similarity H. OLIVA, C. GONZÁLEZ CAMPOS, V. NAVARRO, AND H. H. MOGENA

Human leucocyte antigens in Crohn's disease and ulcerative colitis M. H. GLEESON, J. S. WALKER, J. WENTZEL, J. A. CHAPMAN, AND R. HARRIS

Clinical, microbiological, and immunological studies in patients with immunoglobulin deficiencies and gastrointestinal disorders W. R. BROWN, D. BUTTERFIELD, D. SAVAGE, AND T. TADA
Bacterial agglutination studies with secretory IgA prepared from human gastrointestinal secretions and colostrum D. B. L. MCCLELLAND, R. R. SAMSON, D. M. PARKIN, AND D. J. C. SHEARMAN

Clinical trial of a new carbenoxolone analogue (BX24), zinc sulphate, and vitamin A in the treatment of gastric ulcer P. M. FRASER, RICHARD DOLL, M. J. S. LANGMAN, J. J. MISIEWICZ, AND H. H. SHAWDON

Intraluminal force transducer measurements of human oesophageal peristalsis C. E. POPE II AND P. F. HORTON

Hormone-elicited enzyme release by the small intestinal wall H. GÖTZE, J. W. ADELSON, H. B. HADORN, R. PORTMANN, AND V. TROESCH

Stimulatory effect of pancreozymin-cholecystokinin on calcium secretion in pancreatic juice of dogs $\mathrm{H}$. GOEBELL, Ch. STEFFEN, AND ch. BODE

Progress report The demonstration and function of antibodies in the gastrointestinal tract D. J. C. SHEARMAN, D. M. PARKIN, AND D. B. L. MCCLELLAND Notes and activities

Copies are still available and may be obtained from the PUBLISHING MANAGER, BRITISH MEDICAL ASSOCIATION, TAVISTOCK SQUARE, LONDON, WC1 H 9JR, price $87 \frac{1}{2}$ p. 